CLINICAL STUDY

\title{
Pegvisomant increases intra-abdominal fat in patients with acromegaly: a pilot study
}

\author{
U Plöckinger and T Reuter \\ Interdisziplinäres Stoffwechsel-Centrum: Endokrinologie, Diabetes und Stoffwechsel, Med. Klinik m S Hepatologie und Gastroenterologie, Charité- \\ Universitätsmedizin Berlin, Augustenburger Platz 1, 13353 Berlin, Germany
}

(Correspondence should be addressed to U Plöckinger; Email: ursula.ploeckinger@charite.de)

\begin{abstract}
Objective: Acromegalic patients have increased lipolysis and decreased fat mass as well as reduced insulin sensitivity and glucose intolerance. During somatostatin analog therapy, these changes persist despite GH suppression, but they are now due to drug-induced suppression of insulin secretion. By contrast, during pegvisomant (PEG) therapy, GH no longer stimulates lipolysis due to the blockade of its receptor, while insulin action is unabated. Hence, both insulin sensitivity and fat mass, including intra-abdominal fat, should increase. We therefore studied intra-abdominal fat and insulin resistance in acromegalic patients after a 3-month octreotide-washout period, i.e., during untreated acromegaly, and during PEG treatment.

Methods: Five acromegalic patients, not controlled on octreotide (OCT) therapy, were studied after 3-month OCT washout and 6-month PEG therapy. Insulin sensitivity was determined by homeostatic model assessment value and hyperinsulinemic, normoglycemic clamp. Subcutaneous and intraabdominal fat were measured by electron beam computed tomography.

Results: During PEG therapy, all the patients had normal, age-adjusted IGF-I concentrations. Compared with washout, insulin sensitivity (HOMA and $M$ value) was not significantly different. However, intraabdominal fat mass increased significantly during therapy (median (range) $\mathrm{cm}^{2}: 112(84-480)$ and 172 (112-524) respectively, $P<0.05)$, while subcutaneous fat was not significantly different. Low-density lipoprotein cholesterol, high-density lipoprotein cholesterol, and triglycerides remained unchanged. Conclusions: During PEG therapy of acromegalic patients, intra-abdominal fat increases. Visceral obesity is a risk factor for cardiovascular disease. Hence, confirmation and further studies in a larger cohort of acromegalic patients on PEG treatment are warranted.
\end{abstract}

European Journal of Endocrinology 158 467-471

\section{Introduction}

Somatostatin analogs (SSA) are the primary medical treatment for acromegaly. However, for patients responding insufficiently to SSA, the use of the growth hormone $(\mathrm{GH})$ receptor blocker pegvisomant $(\mathrm{PEG})$ is recommended (1). These two drugs have different effects on lipid and glucose metabolism. Due to the excess GH, untreated acromegaly is associated with increased lipolysis, decreased fat mass, insulin resistance (IR), and deterioration of glucose tolerance (GT). During SSA therapy, insulin that facilitates lipolysis is suppressed by the drug (2). Hence, patients on SSA still have a decreased fat mass and glucose intolerance even if $\mathrm{GH}$ is normalized. By contrast, during PEG therapy, GH no longer stimulates lipolysis due to the blockade of its receptor, while insulin action is unabated. Therefore, insulin sensitivity should improve and fat mass, including intra-abdominal fat, should increase. Visceral obesity is associated with an increased cardiovascular risk $(3,4)$. We therefore investigated intra-abdominal fat mass and insulin sensitivity in five acromegalic patients, who had insufficiently responded to depotoctreotide (OCT) therapy, before and during PEG therapy. They were studied after at least a 3-month OCT-washout period (baseline) and again after 6 months on PEG therapy.

\section{Patients and methods}

We performed a prospective, non-randomized, open study with three female and two male patients, median age 51 years (range 45-73; Table 1). All had active acromegaly and had been on a stable dose of OCT. The dose and the median duration (range) of OCT treatment were $30 \mathrm{mg}$ every 4 weeks for $8.9(2.9-16.8)$ years. During OCT treatment, all patients had failed to fulfill the criteria for biochemical cure of acromegaly (suppression of $\mathrm{GH}$ below $1.0 \mu \mathrm{g} / \mathrm{l}$ during an oral glucose load and age-adjusted normal insulin-like growth factor-I (IGF-I) concentration (5)). Patients were taken off OCT and 
Table 1 Patients' characteristics.

\begin{tabular}{lllll}
\hline Patient & $\begin{array}{l}\text { Age } \\
\text { (years) }\end{array}$ & Sex & $\begin{array}{l}\text { Diagnosis } \\
\text { (year) }\end{array}$ & $\begin{array}{l}\text { Surgery } \\
\text { (year) }\end{array}$ \\
\hline 1 & 46 & $\mathrm{~F}$ & 1986 & 1986 \\
2 & 52 & $\mathrm{~F}$ & 1986 & 1999 \\
3 & 73 & $\mathrm{M}$ & 1991 & 1991 \\
4 & 45 & $\mathrm{M}$ & 1999 & 1999 \\
5 & 73 & $\mathrm{~F}$ & 1986 & 1992 \\
\hline
\end{tabular}

F, female; M, male.

studied at the end of a 3-month washout period (baseline study). PEG was started at $10 \mathrm{mg} / \mathrm{d}$ s.c., and the dose was adjusted every 4 weeks, up to a maximum of $25 \mathrm{mg} / \mathrm{d}$, in order to achieve a serum IGF-I concentration within the age-adjusted normal range. The study protocol was repeated after 6 months on PEG. Substitution therapy was maintained on a stable dose throughout the investigation, with three patients on hydrocortisone, three on L-thyroxine, and one on testosterone. Additional medication, consisting of angiotensin-converting enzyme inhibitors $(N=3)$, hydrochlorothiazide $(N=1)$, and calcium and vitamin $D$ supplementation $(N=3)$ was kept stable throughout.

All tests were performed after an overnight fast. Insulin sensitivity was estimated by a homeostatic model assessment (HOMA-IR value) and by hyperinsulinemic euglycemic clamp ( $M$ value). HOMA-IR was calculated from fasting insulin (mIU/l) and glucose (mmol/l) concentrations by a correctly solved computer model (6) for predicting IR (6-9). HOMA-IR values have been shown to correlate with IR obtained by hyperglycemic and euglycemic clamps $(10,11)$.

For the hyperinsulinemic euglycemic clamp, the subjects were in a supine position with the upper body lifted $\sim 30^{\circ}$ throughout the experiments. The forearm was placed in a heating system maintaining a temperature of $50{ }^{\circ} \mathrm{C}$ in order to obtain arterialized venous blood samples. The patients received a primed insulin infusion at a rate of $2.0 \mathrm{mU} / \mathrm{kg} \times \min ^{-1}$ for $3 \mathrm{~h}$. A C-peptide concentration below the assay sensitivity indicated a complete suppression of endogenous insulin secretion. Blood was drawn every $10 \mathrm{~min}$ for the determination of blood glucose, insulin, and C-peptide. IGF-I was determined in the first sample. The infusion rate of exogenous glucose was adjusted to maintain a glucose concentration of $90 \mathrm{mg} / \mathrm{dl}(5.04 \mathrm{mmol} / \mathrm{l})$. The insulin sensitivity for the systemic glucose uptake was calculated as mean infusion rate of glucose necessary to maintain euglycemia during the last $60 \mathrm{~min}$ of the euglycemic clamp ( $M$ value: $\mathrm{mg}$ glucose $\left.\times \mathrm{kg}^{-1} \times \mathrm{min}^{-1}\right)$.

Blood was centrifuged immediately after withdrawal. Serum for hormone determinations was kept at $-25{ }^{\circ} \mathrm{C}$ until assayed in duplicate as one single batch. The following assays were used: insulin and C-peptide by chemiluminescence enzyme immunoassays (Biermann, Bad Nauheim, Germany and Biochem Immuno Systems, Bologna, Italy, resp.) and IGF-I by RIA-CT
(Mediagnost, Reutlingen, Germany). Assay sensitivity, intra- and inter-assay variation coefficients were $2 \mu \mathrm{U} / \mathrm{ml}, 6.0 \%$ and $5.3 \%$ for insulin; $0.1 \mathrm{ng} / \mathrm{ml}$, $3.34 \%$ and $3.23 \%$ for C-peptide; and $0.107 \mathrm{ng} / \mathrm{ml}$, $7.2 \%$ and $8.6 \%$ for IGF-I. Glucose was determined by a glucose dehydrogenase method (HemoCue, Grossostheim, Germany). Total cholesterol and highdensity lipoprotein (HDL) cholesterol were determined photometrically and low-density lipoprotein (LDL) cholesterol was then calculated as total cholesterol minus HDL cholesterol minus (triglycerides/5) according to Friedewald (12). Intra-abdominal and s.c. fat mass were determined by electron beam computed tomography (Imatron C150, Imatron, San Francisco, CA, USA) with axial abdominal slices $(3 \mathrm{~mm})$ at L2 of the lumbar spine, using numerical analysis of the fat distribution.

\section{Statistical analysis}

For a description of the data, the mean \pm s.e.m. or median (min-max) were used whenever appropriate. Comparisons were calculated using paired $t$-test or Wilcoxon's test for paired samples. Statistical significance was accepted at $P<0.05$.

Informed written consent was obtained from all patients. The study was performed in agreement with the Declaration of Helsinki and the general outlines of the good clinical practice (GCP). The study protocol was approved by the hospital Ethical Committee.

\section{Results}

\section{IGF-I concentration}

At the end of the washout period, the IGF-I concentration was elevated in all five patients. After 6 months on PEG, IGF-I was reduced to within the age-adjusted normal range in all patients (Table 2 ).

Table 2 Insulin-like growth factor-I (IGF-I) concentration (individual values and age-adjusted normal range).

\begin{tabular}{llll}
\hline Patient & $\begin{array}{l}\text { Baseline } \\
\text { (off octreotide) }^{\mathrm{a}}\end{array}$ & Pegvisomant & $\begin{array}{l}\text { Normal } \\
\text { range }^{\mathrm{b}}\end{array}$ \\
\hline 1 & 565 & 227 & $(103-307)$ \\
2 & 772 & 206 & $(97-294)$ \\
3 & 566 & 127 & $(91-284)$ \\
4 & 593 & 243 & $(103-307)$ \\
5 & 376 & 140 & $(91-284)$ \\
Mean士 S.E.M. & $574 \pm 125.6$ & $189 \pm 52.2$ & \\
$P$ value & & $<0.03$ & \\
\hline
\end{tabular}

after 3 months of OCT washout, before PEG therapy.

${ }^{\mathrm{b}} 5-95$ th percentile of the normal, age-adjusted range. 
Table 3 Fat mass $\left(\mathrm{cm}^{2}\right)$, individual, and median values and ratio abdominal/s.c. fat.

\begin{tabular}{|c|c|c|c|c|c|c|}
\hline \multirow[b]{2}{*}{ Patient } & \multicolumn{2}{|c|}{ Intra-abdominal fat } & \multicolumn{2}{|c|}{ S.c. fat } & \multicolumn{2}{|c|}{ Ratio intra-abdominal/s.c. fat } \\
\hline & Baseline $^{a}$ & Pegvisomant & Baseline $^{a}$ & Pegvisomant & Baseline $^{a}$ & Pegvisomant \\
\hline 1 & 112 & 172 & 257 & 284 & 0.44 & 0.61 \\
\hline 2 & 84 & 112 & 145 & 162 & 0.58 & 0.69 \\
\hline 3 & 480 & 524 & 286 & 229 & 1.68 & 2.29 \\
\hline 4 & 160 & 226 & 206 & 202 & 0.78 & 1.12 \\
\hline 5 & 88 & 156 & 182 & 244 & 0.48 & 0.64 \\
\hline Median & 112 & 172 & 206 & 229 & 0.58 & 0.69 \\
\hline Range & $(84-480)$ & $(112-524)$ & $(145-286)$ & $(162-284)$ & $(0.44-1.68)$ & $(0.61-2.29)$ \\
\hline$P$ value & & $<0.05$ & & NS & & $<0.05$ \\
\hline
\end{tabular}

${ }^{\text {aDDuring }} 3$ months of OCT washout, before PEG therapy.

\section{Intra-abdominal and s.c. fat}

The intra-abdominal fat mass increased significantly during PEG therapy $(P<0.05)$ compared with baseline, as did the ratio intra-abdominal/s.c. fat. The s.c. fat mass also increased but to a lesser degree and this change was not significant (Table 3).

\section{IR and glucose metabolism}

The median values for HOMA-IR and the $M$ value (clamp studies) were not significantly different between baseline and PEG (Table 4). Analyzed individually, the HOMA-IR value decreased slightly in three (indicating increased insulin sensitivity) and increased in two patients. The $M$ value as well increased slightly in three patients (again indicating higher insulin sensitivity) and decreased slightly in two patients compared with baseline. Thus, overall on PEG treatment, the indices of glucose metabolism were not uniformly and significantly different from baseline, i.e., from untreated acromegaly.

\section{Plasma cholesterol and triglycerides}

LDL cholesterol, HDL cholesterol, and triglycerides were slightly higher during PEG therapy, but the LDL to HDL ratio improved slightly from $3.25 \pm 0.78$ to $2.83 \pm 0.36$. However, these differences were not significant (Table 5).

\section{Discussion}

PEG therapy effectively normalized IGF-I in all five patients, as has been previously shown by others (13).

Table 4 Glucose sensitivity data (median, min-max).

\begin{tabular}{lllr}
\hline & Baseline $^{\mathrm{a}}$ & Pegvisomant & $\boldsymbol{P}$ \\
\hline HOMA & $3.11(0.74-4.65)$ & $2.81(0.51-5.10)$ & NS \\
$M$ value (clamp) & $2.14(0.63-8.78)$ & $2.30(0.56-9.26)$ & NS
\end{tabular}

${ }^{\text {aDDuring }} 3$ months of OCT washout, before PEG therapy.
It also significantly increased their intra-abdominal fat mass. Untreated acromegalic patients have a decreased fat mass due to the lipolytic effect of GH. Increased lipolysis also causes IR and deterioration of GT. If GH is normalized by a surgery, the increased lipolysis will disappear and the fat mass, insulin sensitivity, and GT will subsequently normalize. However, if $\mathrm{GH}$ is normalized by SSA therapy, the drug-induced suppression of insulin secretion, directly and via suppression of GLP-1 (2), increases lipolysis. Hence, the decreased fat mass and glucose intolerance persist, but they are now drug induced. By contrast, during PEG therapy, $\mathrm{GH}$ no longer stimulates lipolysis due to the blockade of its receptor, while insulin action is unabated. Therefore, insulin sensitivity should improve and fat mass, including intra-abdominal fat, should increase. Thus, our finding of increased fat mass is compatible with the known mode of action of PEG. It could be argued that the increase of intra-abdominal fat may be partly time or age related. However, the age-related increase (between 35 and 74 years) in fat mass index $\left(\mathrm{kg} / \mathrm{m}^{2}\right)$ is only 0.012 and 0.028 per 6 months in healthy male and female subjects respectively (14). Hence, it is much too small to explain a substantial part of the observed increase in our patients.

There was also a slight increase of s.c. fat, but this was not significant. S.c. fat is less important than visceral fat for IR and as a cardiovascular risk factor $(15,16)$. The preponderance of the increase of visceral over s.c. fat may be due to locally increased $11 \beta$-hydroxysteroid dehydrogenase (11 $\beta$ HSD-I) activity. The type-I isoform of $11 \beta \mathrm{HSD}-\mathrm{I}$ that converts cortisone to cortisol is more concentrated in visceral than in s.c. fat. $11 \beta \mathrm{HSD}-\mathrm{I}$ is inhibited by GH (17). The increased local $11 \beta \mathrm{HSD}-\mathrm{I}$

Table 5 Lipid concentrations (mean \pm S.E.M., mmol/l).

\begin{tabular}{|c|c|c|c|}
\hline & Baseline $^{a}$ & Pegvisomant & $P$ \\
\hline LDL cholesterol & $3.56 \pm 0.44$ & $3.74 \pm 0.21$ & NS \\
\hline HDL cholesterol & $1.26+0.10$ & $1.42+0.18$ & NS \\
\hline Ratio LDL/HDL ${ }^{\mathrm{b}}$ & $3.25 \pm 0.78$ & $2.83 \pm 0.36$ & NS \\
\hline Triglycerides & $1.67+0.27$ & $1.90+0.40$ & NS \\
\hline
\end{tabular}

aDuring 3 months of OCT washout, before PEG therapy.

${ }^{\mathrm{b}}$ Mean of individual ratios. 
activity due to the lack of GH-induced inhibition may be a factor in the more pronounced increase of visceral when compared with s.c. fat during PEG therapy (18).

Contrary to expectation, our patients showed no significant improvement of GT. This is in contrast to the finding of Colao et al. (19) who also studied acromegalic patients during PEG therapy following an OCT washout. On the other hand, our findings are in line with the results demonstrating either unaffected or even diminished GT during short-term PEG treatment of healthy subjects (20-22). Moreover, it appears that the improvement of GT during PEG therapy is variable and more pronounced in patients with the poorest GT prior to PEG therapy $(19,23)$. However, an improvement of GT may have been masked in our study by the small number of patients, three of whom had an amelioration and two a deterioration of GT. Two other studies that have also found improved GT during PEG therapy $(23,24)$ are not compatible. In these studies, the comparison was made between GT during OCT and PEG therapies respectively rather than after an OCT washout and PEG therapy. OCT suppresses insulin secretion $(2,25)$. Therefore, GT will be poor even in the presence of normalized GH concentrations. PEG, on the other hand, has no effect on the insulin secretion and hence the removal of GH-induced IR by the GH receptor blockade diminishes lipolysis. Thus, an improvement of GT is to be expected when a patient is directly transferred from OCT to PEG therapy.

We found increased visceral obesity but no improvement of GT, although our patients had normal IGF-I concentrations. We speculate that this combination could also alternatively point to the development of GH deficiency (GHD) during PEG therapy. GHD may be present despite a normal IGF-I concentration (26). It is also known that GHD causes IR $(27,28)$. In a model of PEG-induced GHD (in healthy adults), IR developed in the liver and the muscle but not in the adipose tissue (20). PEG-induced GHD would therefore be compatible with a combination of increased obesity and glucose intolerance. However, this speculation needs to be investigated by further studies.

\section{Acknowledgements}

This investigation was supported by an unrestricted grant from Pfizer Pharma.

\section{References}

1 Melmed S, Casanueva FF, Cavagnini F, Chanson P, Frohman L, Grossman A, Ho K, Kleinberg D, Lamberts S, Laws E, Lombardi G, Vance ML, Werder KV, Wass J \& Giustina A. Guidelines for acromegaly management. Journal of Clinical Endocrinology and Metabolism $2002874054-4058$.

2 Plockinger U, Holst JJ, Messerschmidt D, Hopfenmuller W \& Quabbe HJ. Octreotide suppresses the incretin glucagon-like peptide (7-36) amide in patients with acromegaly or clinically nonfunctioning pituitary tumors and in healthy subjects. European Journal of Endocrinology 1999140 538-544.

3 Wilson PW \& Kannel WB. Obesity, diabetes, and risk of cardiovascular disease in the elderly. American Journal of Geriatric Cardiology 200211 119-123 (125).

4 Garrison RJ, Higgins MW \& Kannel WB. Obesity and coronary heart disease. Current Opinion in Lipidology 19967 199-202.

5 Giustina A, Barkan A, Casanueva FF, Cavagnini F, Frohman L, Ho K, Veldhuis J, Wass J, Von Werder K \& Melmed S. Criteria for cure of acromegaly: a consensus statement. Journal of Clinical Endocrinology and Metabolism 200085 526-529.

6 Levy JC, Matthews DR \& Hermans MP. Correct homeostasis model assessment (HOMA) evaluation uses the computer program. Diabetes Care 199821 2191-2192.

7 Matthews DR, Hosker JP, Rudenski AS, Naylor BA, Treacher DF \& Turner RC. Homeostasis model assessment: insulin resistance and beta-cell function from fasting plasma glucose and insulin concentrations in man. Diabetologia 198528 412-419.

8 Matthews DR, Rudenski AS, Burnett MA, Darling P \& Turner RC. The half-life of endogenous insulin and C-peptide in man assessed by somatostatin suppression. Clinical Endocrinology 1985 23 71-79.

9 Wallace TM, Levy JC \& Matthews DR. Use and abuse of HOMA modeling. Diabetes Care 200427 1487-1495.

10 Katsuki A, Sumida Y, Gabazza EC, Murashima S, Furuta M, ArakiSasaki R, Hori Y, Yano Y \& Adachi Y. Homeostasis model assessment is a reliable indicator of insulin resistance during follow-up of patients with type 2 diabetes. Diabetes Care 200124 $362-365$.

11 Emoto M, Nishizawa Y, Maekawa K, Hiura Y, Kanda H, Kawagishi T, Shoji T, Okuno Y \& Morii H. Homeostasis model assessment as a clinical index of insulin resistance in type 2 diabetic patients treated with sulfonylureas. Diabetes Care 199922 818-822.

12 Friedewald WT, Levy RI \& Fredrickson DS. Estimation of the concentration of low-density lipoprotein cholesterol in plasma, without use of the preparative ultracentrifuge. Clinical Chemistry 197218 499-502.

13 Trainer PJ, Drake WM, Katznelson L, Freda PU, Herman-Bonert V, Van Der Lely AJ, Dimaraki EV, Stewart PM, Friend KE, Vance ML, Besser GM, Scarlett JA, Thorner MO, Parkinson C, Klibanski A, Powell JS, Barkan AL, Sheppard MC, Malsonado M, Rose DR, Clemmons DR, Johannsson G, Bengtsson BA, Stavrou S, Kleinberg DL, Cook DM, Phillips LS, Bidlingmaier M, Strasburger CJ, Hackett S, Zib K, Bennett WF \& Davis RJ. Treatment of acromegaly with the growth hormone-receptor antagonist pegvisomant. New England Journal of Medicine 2000342 1171-1177.

14 Schutz Y, Kyle UU \& Pichard C. Fat-free mass index and fat mass index percentiles in Caucasians aged 18-98 y. International Journal of Obesity and Related Metabolic Disorders 200226 953-960.

15 Kahn BB \& Flier JS. Obesity and insulin resistance. Journal of Clinical Investigation 2000106 473-481.

$16 \mathrm{Kahn}$ SE, Hull RL \& Utzschneider KM. Mechanisms linking obesity to insulin resistance and type 2 diabetes. Nature $2006 \mathbf{4 4 4} 840-846$.

17 Trainer PJ, Drake WM, Perry LA, Taylor NF, Besser GM \& Monson JP. Modulation of cortisol metabolism by the growth hormone receptor antagonist pegvisomant in patients with acromegaly. Journal of Clinical Endocrinology and Metabolism $2001862989-2992$.

18 Bujalska IJ, Kumar S, Hewison M \& Stewart PM. Differentiation of adipose stromal cells: the roles of glucocorticoids and 11ß-hydroxysteroid dehydrogenase. Endocrinology 1999140 3188-3196.

19 Colao A, Pivonello R, Auriemma RS, De Martino MC, Bidlingmaier M, Briganti F, Tortora F, Burman P, Kourides IA, Strasburger CJ \& Lombardi G. Efficacy of 12-month treatment with the $\mathrm{GH}$ receptor antagonist pegvisomant in patients with acromegaly resistant to long-term, high-dose somatostatin analog treatment: effect on IGF-I levels, tumor mass, hypertension and glucose tolerance. European Journal of Endocrinology $2006 \mathbf{1 5 4}$ $467-477$. 
20 Muller AF, Janssen JA, Hofland LJ, Lamberts SW, Bidlingmaier M, Strasburger CJ \& Van Der Lely AJ. Blockade of the growth hormone (GH) receptor unmasks rapid GH-releasing peptide-6-mediated tissue-specific insulin resistance. Journal of Clinical Endocrinology and Metabolism 200186 590-593.

21 Muller AF, Janssen JA, Lamberts SW, Bidlingmaier M, Strasburger CJ, Hofland L \& Van Der Lely AJ. Effects of fasting and pegvisomant on the GH-releasing hormone and GH-releasing peptide- 6 stimulated growth hormone secretion. Clinical Endocrinology 200155 461-467.

22 Parkinson C, Drake WM, Wieringa G, Yates AP, Besser GM \& Trainer PJ. Serum lipoprotein changes following IGF-I normalization using a growth hormone receptor antagonist in acromegaly. Clinical Endocrinology 200256 303-311.

23 Barkan AL, Burman P, Clemmons DR, Drake WM, Gagel RF, Harris PE, Trainer PJ, Van Der Lely AJ \& Vance ML. Glucose homeostasis and safety in patients with acromegaly converted from long-acting octreotide to pegvisomant. Journal of Clinical Endocrinology and Metabolism 200590 5684-5691.

24 Drake WM, Rowles SV, Roberts ME, Fode FK, Besser GM, Monson JP \& Trainer PJ. Insulin sensitivity and glucose tolerance improve in patients with acromegaly converted from depot octreotide to pegvisomant. European Journal of Endocrinology $2003149521-527$.

25 Baldelli R, Battista C, Leonetti F, Ghiggi MR, Ribaudo MC, Paoloni A, D'amico E, Ferretti E, Baratta R, Liuzzi A, Trischitta V \& Tamburrano G. Glucose homeostasis in acromegaly: effects of long-acting somatostatin analogues treatment. Clinical Endocrinology 2003 $59492-499$.

26 Paisley AN \& Trainer PJ. The challenges of reliance on insulin-like growth factor I in monitoring disease activity in patients with acromegaly. Hormone Research 200462 (Suppl 1) 83-88.

27 Abdul Shakoor SK \& Shalet SM. Effects of GH replacement on metabolism and physical performance in GH deficient adults. Journal of Endocrinological Investigation 200326 911-918.

28 Johannsson G \& Bengtsson BA. Growth hormone and the metabolic syndrome. Journal of Endocrinological Investigation $19992241-46$.

Received 31 December 2007

Accepted 16 January 2008 